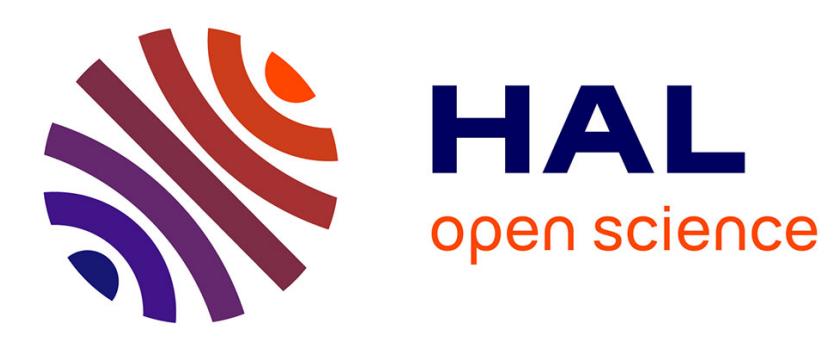

\title{
Superenhancement of Precipitation at the Center of Tropical Islands
}

\author{
Max Ulrich, Gilles Bellon
}

\section{To cite this version:}

Max Ulrich, Gilles Bellon. Superenhancement of Precipitation at the Center of Tropical Islands. Geophysical Research Letters, 2019, 46 (24), pp.14872 - 14880. 10.1029/2019g1084947 . hal-03086305

\section{HAL Id: hal-03086305 https://hal.science/hal-03086305}

Submitted on 22 Dec 2020

HAL is a multi-disciplinary open access archive for the deposit and dissemination of scientific research documents, whether they are published or not. The documents may come from teaching and research institutions in France or abroad, or from public or private research centers.
L'archive ouverte pluridisciplinaire HAL, est destinée au dépôt et à la diffusion de documents scientifiques de niveau recherche, publiés ou non, émanant des établissements d'enseignement et de recherche français ou étrangers, des laboratoires publics ou privés. 


\title{
Super-Enhancement of Precipitation at the Center of Tropical Islands
}

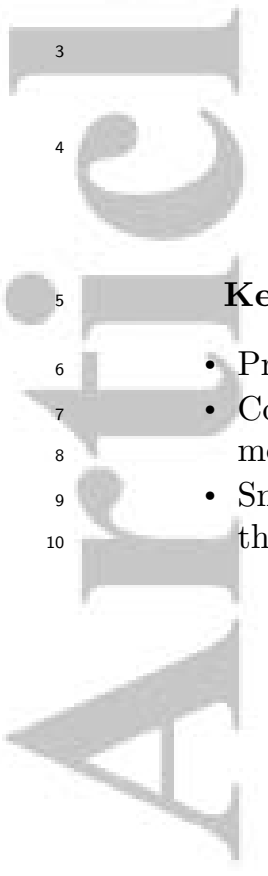

\author{
Max Ulrich $^{1}$, Gilles Bellon ${ }^{1}$ \\ ${ }^{1}$ Department of Physics, University of Auckland
}

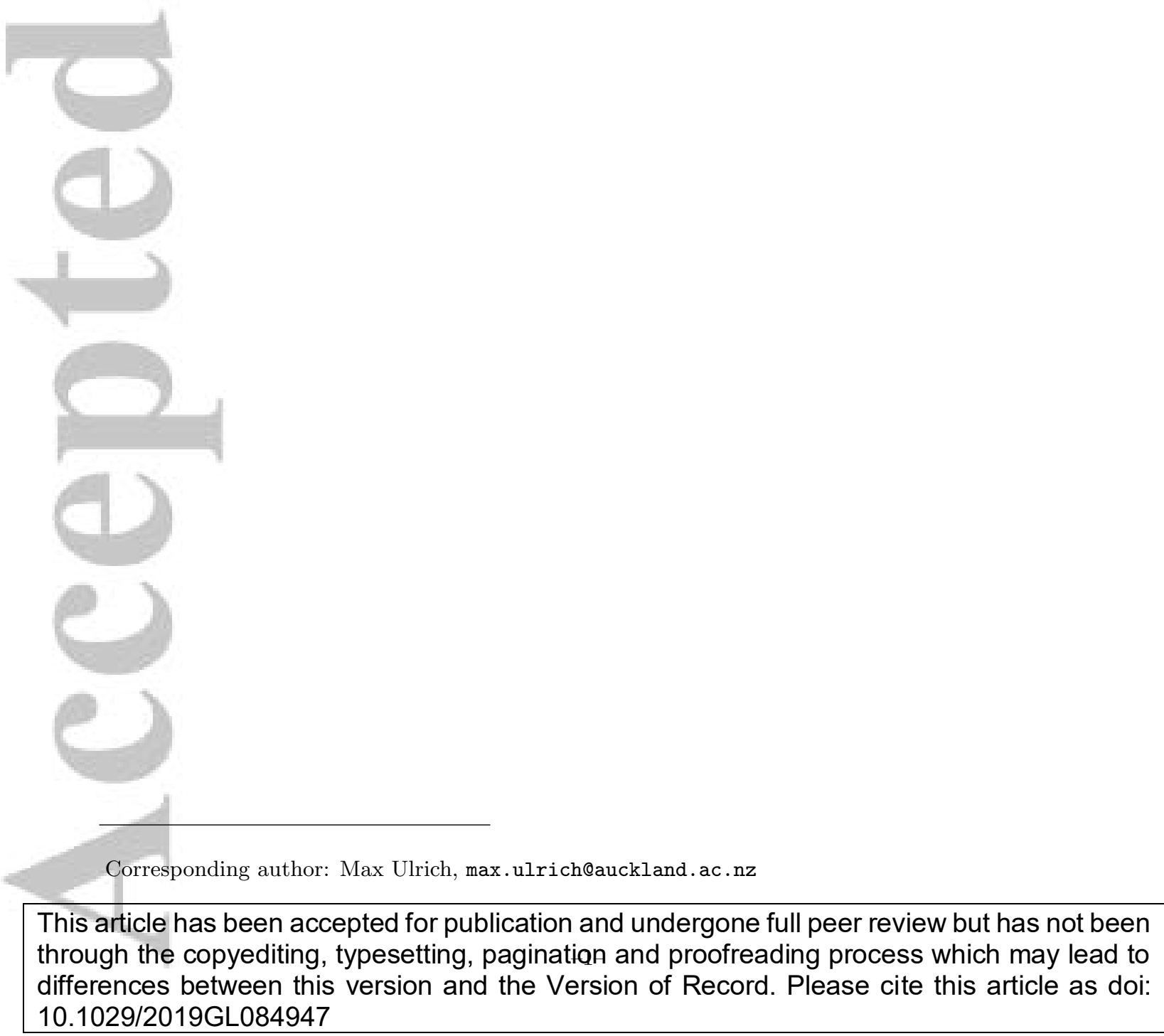




\section{$11 \quad$ Abstract \\ 12 We identified a canonical pattern of the Diurnal Cycle (DC) of precipitation on trop- ical islands, with exceptions for small and very large islands, using an 18-year climatol- ogy of satellite estimates. Medium to large islands receive more precipitation than the surrounding ocean with super-enhancement of precipitation in their center respective to their periphery. Differential heating of the island surface generates a Sea Breeze Front (SBF) propagating inland in the afternoon, triggering precipitation. SBF segments from different coasts meet in the island center, further invigorating precipitation. Small is- lands exhibit neither DC nor precipitation enhancement most likely because ventilation prevents the genesis of the Land-Sea Breeze Circulation (LSBC). On the largest islands the SBFs decay after sunset before reaching the center, hence the super-enhancement is not significant, also precipitation lasts longer and cloud remnants delay the DC on the next day, which we attribute to the presence of high mountains.}

\section{$24 \quad$ Plain Language Summary}

25 Satellite estimates of rainfall show that medium to large tropical islands receive more

26 rain than the surrounding ocean and rainfall amounts are even higher at the center of 27 these islands. The increased precipitation is caused by the surface and atmospheric di${ }_{28}$ urnal cycle. Land heats faster than the ocean in the morning, and a sea breeze develops. The sea breeze lifts the warm and moist air over the island and the rising air condenses as it cools with ascent, forming clouds and thus rainfall. The sea breeze penetrates inland during the afternoon and meets the sea breeze from other coasts of the island in its center which further enhances rainfall. Small islands do not exhibit this behavior most likely because the wind transports warm surface air away from the island and brings cool air from the sea, preventing the sea breeze formation and the development of a diurnal cycle. The largest islands are too big for the sea breeze segments to meet in their cen-

36 ter before sunset, thus no super-enhancement of rainfall occurs in the center of these is-

37 lands.

\section{Introduction}

39 The diurnal cycle (DC) of precipitation on tropical islands has strong societal im40 pacts, providing water regularly for human activities. Fortunately, large islands seem to be a focal point for deep convection and precipitation: it rains more on these islands than 42 on the surrounding ocean (Sobel et al., 2011). This island enhancement of precipitation

43 is generally attributed to the diurnal cycle (Sobel et al., 2011; Cronin et al., 2015), al-

44 though mechanical forcing could play a role for large low-level wind speeds (Wang \& So45 bel, 2017).

46 Tropical precipitation peaks in the afternoon over land and at night or in the early

47 morning over the ocean (Yang \& Slingo, 2001). Three large-scale regimes can be iden48 tified (Kikuchi \& Wang, 2008): continental, maritime and coastal regimes. The conti49 nental and maritime regimes have diurnal rainfall peaking, respectively, in the evening ${ }_{50}$ and late night without systematic propagation patterns. In contrast, the coastal regime ${ }_{51}$ consists of daytime precipitation propagating inland from the coast and nighttime rain52 fall propagating offshore (Mori et al., 2004; Kikuchi \& Wang, 2008). The main mech${ }_{53}$ anisms of coastal precipitation are understood (Wu et al., 2008; Love et al., 2011; Cronin ${ }_{54} \quad$ et al., 2015; Liang \& Wang, 2017; Liang et al., 2017): the small heat capacity of land com55 pared to that of the surface ocean results in a faster warming of the land surface by day 56 and a faster cooling by night. The resulting temperature gradient generates the land57 sea breeze circulation (LSBC), a shallow overturning circulation with a surface sea breeze ${ }_{58} \quad$ by day and a land breeze by night. The sea breeze propagates inland during the day with 59 a frontal boundary between cool, stable maritime and warm, unstable island air, called ${ }_{60}$ the sea breeze front (SBF). Surface convergence at the SBF results in deep moist con-

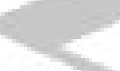


vection. At night convection is caused by the land-breeze front which propagates offshore, sometimes quite far with the help of gravity waves (Zhou \& Wang, 2006; Hassim et al., 2016; Coppin \& Bellon, 2019a, 2019b).

However, it is still unclear why the DC varies significantly from day to day and from island to island, i.e., how the geographical characteristics of the island and the surrounding large-scale conditions influence the DC. Analysis of satellite estimates of precipitation on small tropical islands has shown that the size of these islands and the maximum altitude are important factors in determining the DC of precipitation (Sobel et al., 2011). The strength of the DC of precipitation depends on the solar irradiance received at the surface. Studies of the interaction of the eastward propagating Madden-Julian Oscillation (MJO) with the DC over the Maritime Continent and found that the strongest DC is observed before the MJO precipitation anomaly arrives (Peatman et al., 2014; Hagos et al., 2016), when the large-scale convection is inhibited and the solar insolation is maximum. During the active phase of the MJO, the DC and island precipitation is reduced. Also, the DC in the Maritime Continent can feed back onto the MJO and be responsible for the barrier effect of the Maritime Continent on the propagation of the MJO (Majda \& Yang, 2016; Hagos et al., 2016).

Incorrect representation of the DC on tropical islands accounts for large biases in climate models (Neale \& Slingo, 2003; Schiemann et al., 2014), especially large negative biases over the Maritime Continent. This results in an underestimation of the tropical precipitation and causes errors in the representation of the global circulation (Schiemann et al., 2014). The coarse resolution of global climate models is responsible for these biases, since the geography of coasts varies on smaller scales and most coastal atmospheric processes occur on these scales. Parameterization of the coastal gradients and precipitation would help reducing coastal precipitation biases. A thorough understanding of the DC - the largest source of precipitation variability (Janowiak et al., 2005) - is crucial in accomplishing this task.

In our study, we use a climatology of satellite estimates to investigate precipitation and its DC on tropical islands, and in particular how the island size influences the DC of precipitation. The following section describes the dataset we used and the methodology. Section 3 presents our results and Section 4 presents a discussion of these results which suggest a classification of islands in three different categories. Section 5 presents concluding remarks and perspectives.

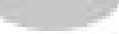

\section{Data and Methods}

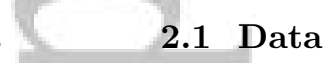

For this study, we use high resolution satellite estimates of precipitation, the NOAA Climate Prediction Centre Morphing Method (CMORPH) (Joyce et al., 2004). The high temporal resolution of geostationary satellite data is used to propagate precipitation patterns derived from passive microwave imagery obtained from polar orbiting satellites (Joyce et al., 2004). Shape and intensity of the precipitation features are morphed from one time step to another by using temporal weights (Joyce et al., 2004). The product has a temporal resolution of 30 minutes and a horizontal resolution of about $8 \mathrm{~km}$. For this study, we use a period of 18 years, from 1988 to 2015 . The data is organized according to the Local sun-relative Time (LT) to provide a comparable time axis for all datapoints.

The topography dataset NGDC Topographical Dataset (ETOPO1) described by Amante and Eakins (2009) is used to determine position, size and altitude as well as the distance from the coast of island gridpoints between $30^{\circ} \mathrm{N}$ and $30^{\circ} \mathrm{S}$.

Surface wind vectors for the period 1998 - 2015 are obtained from the Cross-Calibrated Multi Platform Surface Winds (CCMP) surface wind vector product (Atlas et al., 2011) with a horizontal resolution of $25 \mathrm{~km}$ and a temporal resolution of 6 hours. 
111

112

113

$116 \quad$ - A1 : $100<\mathrm{A} \leq 2,000 \mathrm{~km}^{2} \quad\left(515\right.$ islands, total area: $\left.195,482 \mathrm{~km}^{2}\right)$

117

118

119

119

120

121

122

123

124

125

126

127

128

The islands are stratified according to their area "A" to identify the influence of size on the DC of precipitation. A minimum area threshold of $100 \mathrm{~km}^{2}$ is applied to ensure, that the area of islands under consideration covers at least one CMORPH gridpoint (approximately $64 \mathrm{~km}^{2}$ ). The islands are divided into the following five area classes:

- A2 : $2,000<\mathrm{A} \leq 8,000 \mathrm{~km}^{2} \quad\left(49\right.$ islands, total area: $191,962 \mathrm{~km}^{2}$ )

- A3 : $8,000<\mathrm{A} \leq 32,000 \mathrm{~km}^{2} \quad\left(21\right.$ islands, total area: $\left.273,800 \mathrm{~km}^{2}\right)$

- A4 : $32,000<\mathrm{A} \leq 128,000 \mathrm{~km}^{2}$ (9 islands, total area: $689,955 \mathrm{~km}^{2}$ )

- A5 : $\quad \mathrm{A}>128,000 \mathrm{~km}^{2}$ (5 islands, total area: $2,736,986 \mathrm{~km}^{2}$ )

CMORPH gridpoints are also stratified according to their distance from the coast. Topological regions such as the surrounding ocean, the island's periphery and the island's center are defined using the the distance from the coast normalized by the maximum distance $\mathrm{D}_{\max }$ to the coast for each island. The surrounding ocean is defined, similarly as in Sobel et al. (2011), as the oceanic gridpoints within $3 \mathrm{D}_{\max }$ or $210 \mathrm{~km}$, whichever is smaller. Island gridpoints within half of $\mathrm{D}_{\max }$ from the coast are considered part of the island's periphery. Gridpoints further than $75 \%$ of $\mathrm{D}_{\max }$ from the coast are considered in the central region of the island. Quantities over one of the regions defined above is denoted by the subscript "O" for surrounding ocean, "P" for island periphery, and "C" for center.

The precipitation data is averaged over the length of the dataset to compute the long-term average total daily precipitation rate $\overline{\mathrm{P}}$ and the composite diurnal cycle $\mathrm{P}(\mathrm{t})$ for each gridpoint. In this study we express the amplitude $\overline{\mathrm{P}}_{\mathrm{DC}}$ of the $\mathrm{DC}$ as the integral over the day $\int_{d}$ of the difference between $\mathrm{P}(\mathrm{t})$ and the daily average precipitation rate $\langle\overline{\mathrm{P}}\rangle$ :

$$
\overline{\mathrm{P}}_{\mathrm{DC}}=\int_{d}|\mathrm{P}(t)-\langle\overline{\mathrm{P}}\rangle|
$$

For islands in area classes A1, A2 and A3 we also compute the long-term mean wind speed $\overline{\mathrm{U}}$ and the average island width $\mathrm{D}_{\text {cross }}$ in the direction of this long-term mean wind. The ventilation time scale $\tau_{v}$, defined as the ratio of these two quantities, is the typical amount of time needed for the mean wind to transport air across the island:

$$
\tau_{v}=\frac{\mathrm{D}_{\text {cross }}}{\overline{\mathrm{U}}} .
$$

\section{Results}

Figure 1a shows the 1998 - 2015 climatology of daily precipitation rate for each area class. It is clearly visible in figure 1a that islands in A1 receive relatively low precipitation amounts, about $3.5 \mathrm{~mm} \mathrm{~d}^{-1}$, islands in A2, A3 and A4 moderate amounts of around $5 \mathrm{~mm} \mathrm{~d}^{-1}$ and the largest islands show about $7 \mathrm{~mm} \mathrm{~d}^{-1}$. All but one island in class $\mathrm{A} 5$ are located in regions of long-term mean ascent favoring precipitation, while a majority of smaller islands are located in the drier subtropics (not shown), and this contributes to the more intense precipitation on the largest islands. On islands in A1 the daily precipitation is very similar in all three topological regions. On islands in categories A2 to A5 , we can see the known island precipitation enhancement (Sobel et al., 2011; Cronin et al., 2015): it rains more on the island than over the surrounding ocean. More precisely, it rains more in the center of the island than over the surrounding ocean, and except for islands in A2, it rains more on the island periphery than over the surrounding ocean. Table 1 displays the ratios of long-term mean precipitation between the different regions; statistically significant ratios at a $99 \%$ confidence level are determined by a KolmogorovSmirnof test. The enhancement in the center relative to the periphery is statistically sig-

\subsection{Methods}



nificant for A2 (13\%), A3 (14\%) and A4 (24\%). For islands in A5 we found a non-significant enhancement of $6 \%$. The periphery of islands in A1 and A2 does not receive more precipitation than the surrounding ocean, however islands bigger than $8,000 \mathrm{~km}^{2}$ (A3, A4, and A5) exhibit significantly more precipitation over the island's periphery (table 1). When we compare the daily precipitation maximum over the island center with the surrounding ocean $\mathrm{P}_{\max , \mathrm{c}} / \mathrm{P}_{\max , \mathrm{p}}$, enhancement of precipitation is significant for categories A2 to A5 and reaches up to $75 \%$ in class A4. There is therefore a super-enhancement of precipitation in the center of tropical islands over medium-size islands (classes A2-A4), compared to their periphery, and some hint of this enhancement for the largest islands. Since island precipitation enhancement is attributed to the DC (Sobel et al., 2011; Cronin et al., 2015), we investigate the differences in the DC between the different regions. In Figure 1 we display the long-term composite DC of precipitation in the island periphery (b) and center (c) for each area class. There is essentially no diurnal cycle of precipitation over small islands (A1). Over bigger islands (A2-A5), there is a DC with a peak in the afternoon or evening; which occurs later over larger islands. Over mediumto-large islands (classes A2-A4), precipitation starts around the same time at $9 \mathrm{am}$. Over the largest islands (class A5), precipitation extends into the night until the early morning, and the onset of precipitation in the morning appears somewhat delayed, particularly in the periphery of the islands. We find significant super-enhancement of the peak precipitation rate in classes $\mathrm{A} 2$ to $\mathrm{A} 5$, with a maximum for $\mathrm{A} 4$ (table 1). The fraction of the day with rain rates above the nocturnal base line increases with island area from 3 hours in A2 to 16 hours in A5 (fig. 1). The maximum precipitation occurs only slightly later in the center of the islands in classes A2 and A3, but on bigger islands precipitation peaks significantly later in the center than in the periphery (fig. 1): in A4, the peak is delayed by one hour and in A5 by 2.5 hours.

Figure 2 shows the DC of precipitation stratified by distance from the coast for each area class. The onset of diurnal precipitation occurs at the same time (09-10 LT) over all island regions in classes $\mathrm{A} 2$ to $\mathrm{A} 4$, but over islands in class $\mathrm{A} 5$ the increase in precipitation is delayed inland. The precipitation peak in classes A2 to A5 propagates inland with propagation speeds up to $5.5 \mathrm{~m} \mathrm{~s}^{-1}$ (see supporting material). The precipitation peak also intensifies as it propagates. In classes A2-A4, it reaches a maximum in the center of the island. The peak precipitation rate in the center is largest for islands in classes A3 and A4. On the largest islands in class A5, which include gridpoints further than $128 \mathrm{~km}$ from the coast, the maximum total daily precipitation and precipitation peaks can be found $64-128 \mathrm{~km}$ away from the coast (fig. 2). Over all regions, precipitation decreases to a low baseline level within a few hours on islands in classes A2 to $\mathrm{A} 4$, while it persists longer on islands in $\mathrm{A} 5$.

In contrast to the DC on islands of all other area classes, there is no distinguishable DC of precipitation on the smallest islands in class A1 (fig. 2). The negligible precipitation rates more than $16 \mathrm{~km}$ from the coast in area class A1 (fig. 2a) result from a few gridpoints located on the very dry islands of Tenerife and Gran Canaria.

\section{Summary and Discussion}

Islands larger than $8,000 \mathrm{~km}^{2}$ exhibit a strong DC of precipitation with onset of precipitation on the coast around 09 - $10 \mathrm{LT}$ and inland propagation of precipitation, at a speed up to $5.5 \mathrm{~m} \mathrm{~s}^{-1}$, with a progressive intensification of convection. These islands exhibit enhancement of precipitation with respect to the surrounding ocean. Mediumto-large islands with an area between 8,000 and $128,000 \mathrm{~km}^{2}$ also exhibit super-enhancement of precipitation at the center of the island with respect to the periphery. Over the largest islands, the heaviest precipitation occurs at $64-128 \mathrm{~km}$ from the coast and the superenhancement of precipitation at the center is not significant. Over these largest islands, precipitation persists late into the night after its evening peak and the onset of convection is delayed compared to the smaller islands. On small islands, there is no DC and no enhancement of precipitation. These results suggest that there is a canonical pattern 
211 of island precipitation for medium-to-large islands, and specific behaviors for small and

212 very large islands. In the following, we discuss the most likely mechanisms at play in this 213 canonical pattern and its limits.

The canonical pattern is consistent with the LSBC: as the island surface warms with surface insolation and warms the atmospheric boundary layer above the island, sea-toland temperature gradients create land-to-sea pressure gradients which cause the development of the sea breeze and the associated SBF, separating cooler maritime air from warmer inland air mass. The SBF is advected inland by the sea breeze itself which persists and moves inland thanks to the pressure gradient across the SBF between the maritime air advected by the breeze and the diurnally increasing surface temperature inland. We found inland propagation speeds of the precipitation peak to range from 0 to $5.5 \mathrm{~m} \mathrm{~s}^{-1}$ (see supporting material), which is consistent in direction and speed with the SBF propagation, as documented in previous observational studies (Kingsmill, 1995; Carbone et al., 2000; Suresh, 2007) and in numerical simulations (Dailey \& Fovell, 1999; Fovell \& 225 Dailey, 2001; Fovell, 2005).

226 Convergence of horizontal wind at the SBF creates ascending motion which trig-

227 gers convection. Additional convergence in response to the convective latent heating and

228 moisture-convection feedbacks explain the persistence of convection after the passage of

229 the SBF in coastal regions. These feedbacks and increasing diurnal surface temperatures

230 inland explain the development of convection inland slightly in advance of the SBF and

231 more intense convection than in the coastal regions. Super-enhancement occurs at the

${ }_{232}$ center of the islands where segments of SBFs coming from different directions meet and

233 create intense low-level convergence.

$234 \quad$ An alternative mechanism for the inland propagation of convection is gravity waves, which can cause significant convection by destabilizing the troposphere. On all tropical islands, the composite precipitation peaks propagate at speeds below $6 \mathrm{~m} \mathrm{~s}^{-1}$ (see supporting material). These speeds are smaller that most observed and modeled gravity waves which are found to propagate at speeds between 8 and $20 \mathrm{~m} \mathrm{~s}^{-1}$ (Lane et al., 2001; Mapes et al., 2003; Zhou \& Wang, 2006; Tulich et al., 2007; Lane \& Zhang, 2011; Coppin \& Bellon, 2019a); gravity waves propagating at $5 \mathrm{~m} \mathrm{~s}^{-1}$ and slower could only exist with a very complex baroclinic structure and are therefore unlikely.

${ }_{242}$ Convection decreases after sunset because of the discontinuation of solar forcing
${ }_{243}$ but also because of the convective re-stratification which stabilizes the atmosphere above the island. It is reinforced by cooler air advected by the sea breeze.

${ }_{245}^{245}$ In contrast to the above pattern, Figures 1 and 2 show no precipitation enhance-
ment and no DC on small islands. We hypothesize that this results from an efficient ven-

247 tilation by the mean wind which prevents the development of the LSBC: surface-air anomaly

248 are transported by the mean wind away from the island on time scales small compared

249 to the DC, preventing the development of an island-ocean thermal contrast. Figure 4

${ }_{250}$ shows the mean amplitude $\overline{\mathrm{P}}_{\mathrm{DC}}$ of the DC of precipitation over each island as function 251 of the a ventilation time scale $\tau_{v}$, with indications of island size and precipitation enhance${ }_{252}$ ment. It supports our hypothesis: generally, $\overline{\mathrm{P}}_{\mathrm{DC}}$ increases with $\tau_{v}$ (they are positively 253 correlated, with a Pearson correlation coefficient $\mathrm{R}$ of 0.63 and a regression coefficient ${ }_{254}$ of $\left.\alpha=0.38 \pm 0.04 \mathrm{~mm} \mathrm{~d}^{-2}\right)$. In particular, islands with a short $\tau_{v}(<3 \mathrm{~h})$ exhibit a 255 small diurnal cycle of precipitation with no precipitation enhancement at the center of ${ }_{256}$ the island. Most islands in A1 and A2 are in this category. Precipitation over small is257 lands is dominated by advection of convective systems from the surrounding region.

${ }_{258}$ The DC over the largest islands in area class A5 exhibits similarities with the canon-

259 ical pattern described above. However, we find the strongest DC in a belt $64-128 \mathrm{~km}$

${ }_{260}$ away from the coast with its peak time at around 18:30 LT in the evening which is around

$261 \quad$ sunset (fig. 2e) and decreasing peak precipitation rates in the center. The distance of

262 the maximum precipitation peak from the coast $(64-128 \mathrm{~km})$ corresponds to the dis-

263 tance of propagation at 3 to $5 \mathrm{~m} \mathrm{~s}^{-1}$ between late morning and sunset. After sunset the

264 temperature gradient between land and surrounding sea reverses and hence the frontal

265 gradient at the SBF dissolves, meaning that the SBF vanishes. The distance of propa-

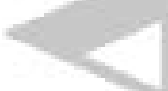

gradien 


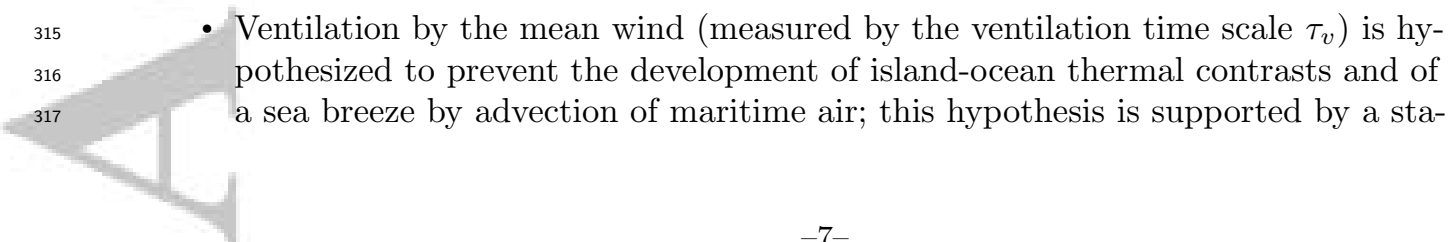
gation is consistent previous modeling results of Dailey and Fovell (1999) who found inland SBF propagation extending no further than $100 \mathrm{~km}$ from the coast, as well as with observational studies (Rani et al., 2010; Planchon et al., 2006). Over very large islands, the SBF either does not reach the center of the island, or reaches it with a reduced intensity. There is therefore only a weak or no super-enhancement of precipitation on these islands. However, the convective precipitation continues to move inland at night, possibly driven by cold pools caused by convective downdrafts (Saito et al., 2001; Zhu et al., 2017).

The "tail" of precipitation lasting throughout the night over these islands also differs from the canonical pattern. A recent modeling study of Coppin and Bellon (2019b) shows that the persistence of precipitation through the night can result from the presence of a mountain range: upslope winds reinforce convection during the day over the mountains and the resulting latent heating maintains upslope convergence long after sunset. All islands in class A5 have tall mountains, with peaks above $2500 \mathrm{~m}$, so we hypothesize that the late-night tail of precipitation over the islands result from this topographic effect. To test this hypothesis, we analyze the islands in class A4; we find prolonged precipitation (the "tail") at night for islands with mountains higher than $2500 \mathrm{~m}$, while no such tail is apparent for islands with mountain tops below $2500 \mathrm{~m}$ (fig. 2f). This orographic effect contributes to the enhancement of precipitation over the whole island compared to the surrounding ocean.

The delayed onset of daily precipitation over islands in A5, with a progressively later onset further inland can be associated to a reduction of solar insolation in the morning caused by enhanced cloud cover resulting from the remnants of nocturnal precipitation systems.

Our results add more detail to the hydrological point of view presented in Ogino et al. (2016) and Ogino et al. (2017), who found that a region of $300 \mathrm{~km}$ offshore to 300 $\mathrm{km}$ inland acts as a "tropical coastal dehydrator" and found that $90 \%$ of the rainiest regions on Earth, defined as mean rain rates above $3500 \mathrm{~mm} \mathrm{y}^{-1}$, are located within 300 $\mathrm{km}$ of a coastline. We found that, for islands, the land-side branch of the coastal region defined by Ogino et al. (2016) receives more precipitation than the sea-side part of this regions and as a result of the DC and the associated LSBC. Our results suggest, that there is a different behavior of coastal precipitation over islands than over big landmasses, where the atmospheric dynamics of moisture are different. Over islands, there is always advection of moisture from the sea, independent of wind direction, whereas along the coastline of big land masses, offshore winds will provide less moisture than onshore winds.

\section{Concluding Remarks and Outlook}

Interestingly, features of the precipitation DC over islands are similar enough that they appear in the composite diurnal cycle averaged over islands of similar size and over the length of the dataset (18 years). We can identify a large number of medium-to-large islands with the same diurnal pattern of convection, which we call the canonical DC. On these islands, precipitation propagates inland from the coast, starting in late morning and intensifying along the propagation until it reaches the center of the island. The propagation speed is consistent with an association with the sea-breeze front. The DC causes more precipitation over the island than over the surrounding ocean area, with precipitation at the center of these islands being further enhanced due to the meeting of SBFs from different coasts of the island. Although most of this canonical pattern is already known (Wu et al., 2008; Love et al., 2011; Cronin et al., 2015; Liang \& Wang, 2017; Liang et al., 2017), the super- enhancement at the center of the island is a novel finding. Both small and very large islands exhibit a distinct pattern from the canonical DC: 

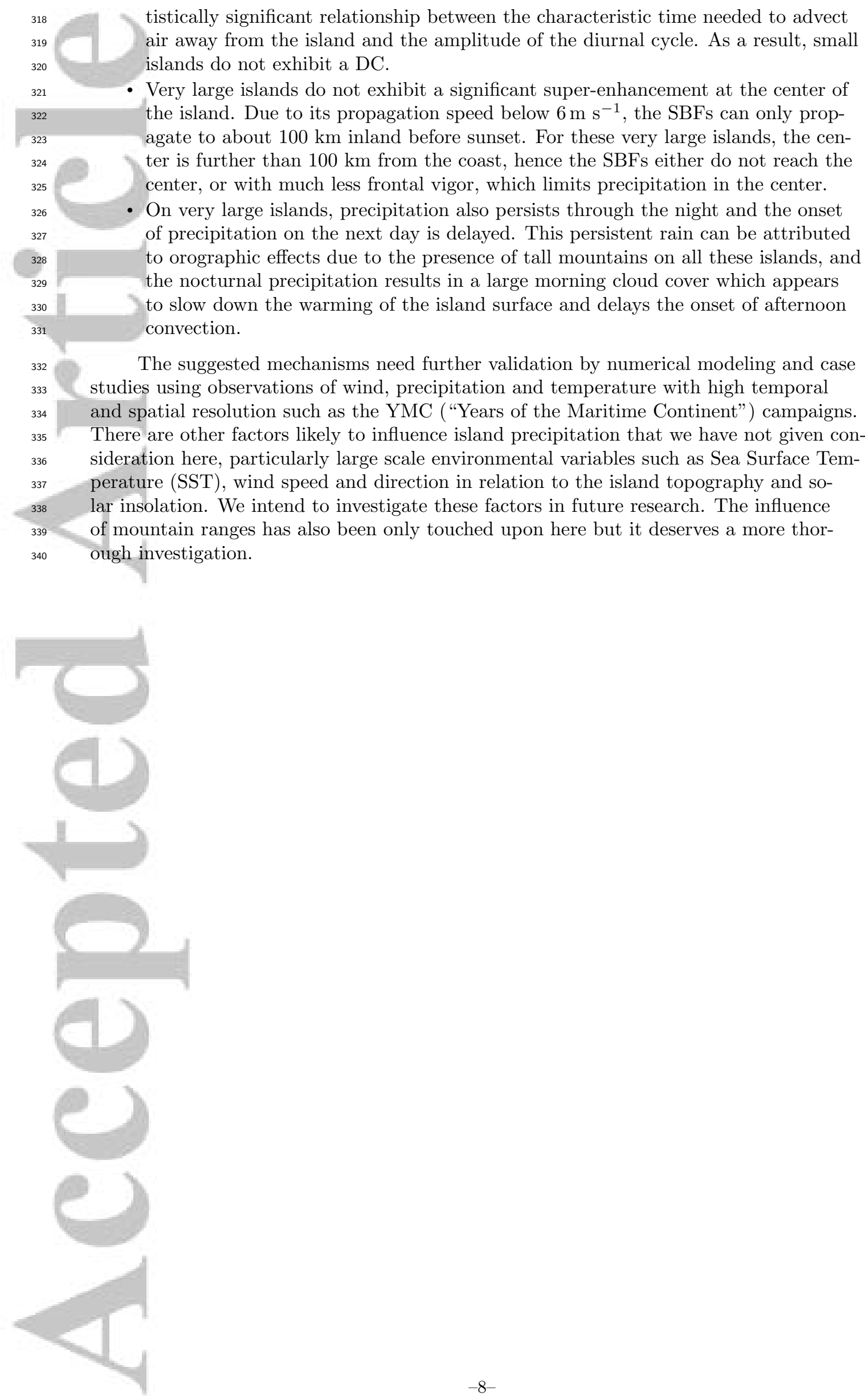


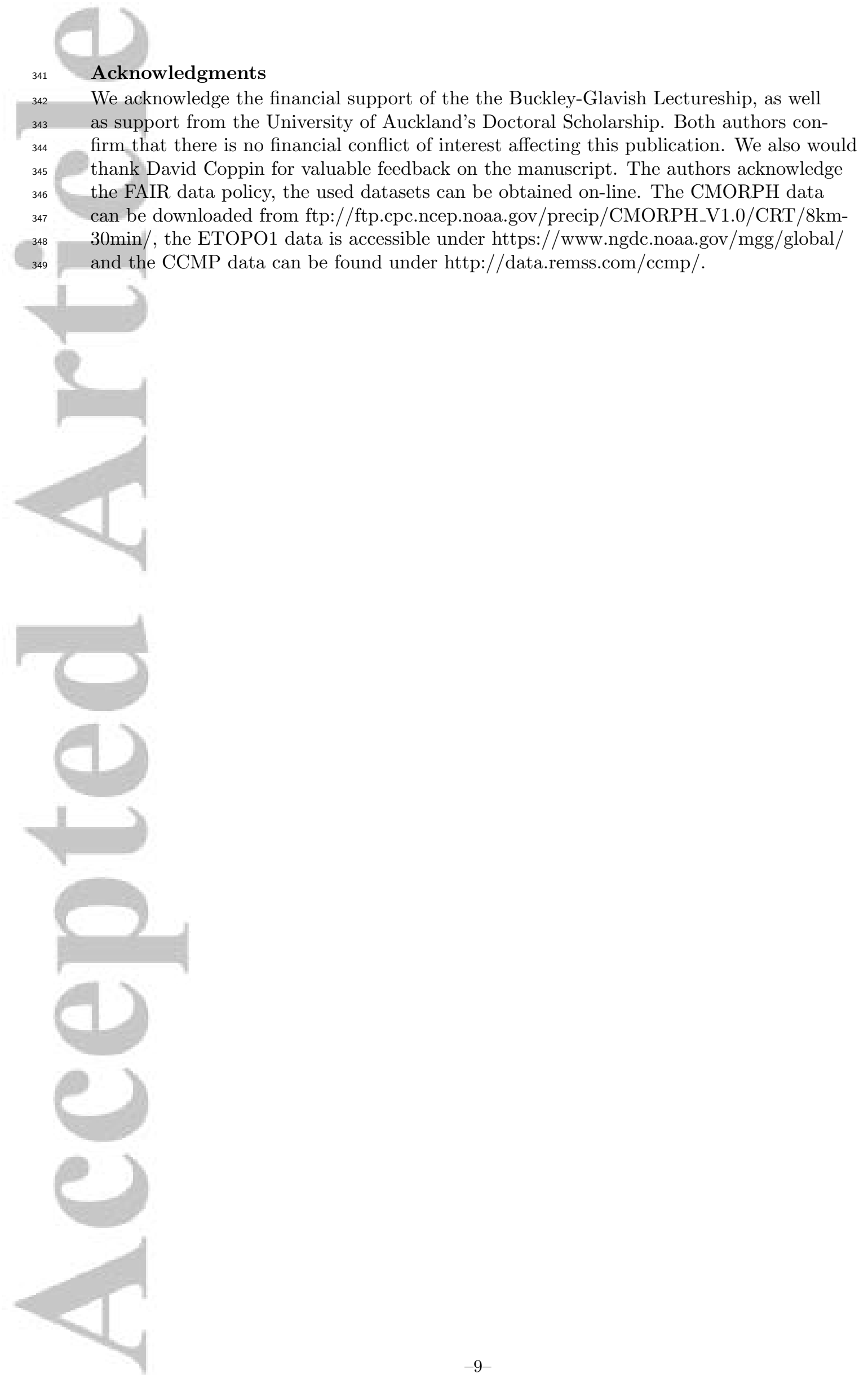


Table 1. Ratios of daily precipitation from topological regions on tropical islands, stratified by area. Statistical significant values at a $99 \%$ confidence level, derived by applying a two-sample KS-test, are printed in bold font.

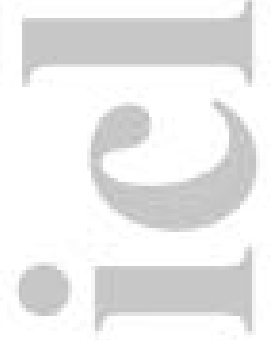

\begin{tabular}{lccccc}
\hline Ratio & $\mathrm{A} 1$ & $\mathrm{~A} 2$ & $\mathrm{~A} 3$ & $\mathrm{~A} 4$ & $\mathrm{~A} 5$ \\
$\overline{\overline{\mathrm{P}_{\mathrm{c}}}} / \overline{\mathrm{P}_{\mathrm{p}}}$ & 1.03 & $\mathbf{1 . 1 3}$ & $\mathbf{1 . 1 4}$ & $\mathbf{1 . 2 4}$ & 1.06 \\
$\overline{\mathrm{P}_{\mathrm{p}}} / \overline{\mathrm{P}_{\mathrm{o}}}$ & 1.03 & 1.00 & $\mathbf{1 . 2 1}$ & $\mathbf{1 . 1 4}$ & $\mathbf{1 . 2 6}$ \\
$\overline{\mathrm{P}_{\mathrm{c}}} / \overline{\mathrm{P}_{\mathrm{o}}}$ & 1.06 & $\mathbf{1 . 1 3}$ & $\mathbf{1 . 3 8}$ & $\mathbf{1 . 4 1}$ & $\mathbf{1 . 3 3}$ \\
$\mathrm{P}_{\max , \mathrm{c}} / \mathrm{P}_{\max , \mathrm{p}}$ & 0.89 & $\mathbf{1 . 1 3}$ & $\mathbf{1 . 6 2}$ & $\mathbf{1 . 7 5}$ & $\mathbf{1 . 2 1}$ \\
\hline
\end{tabular}

Figure 1. a) Average daily rainfall in different topological regions of tropical islands stratified by island area. Area classes A1 to A5 are described in text. DC of precipitation rate on tropical islands stratified by area for the periphery (b) and center(c) of the island.

Figure 2. DC of precipitation for each area category, stratified by distance from the coast (a-e). DC of precipitation stratified by maximum altitude in $\mathrm{A} 4$ (f)

Figure 3. Scatterplot of the ventilation time scale $\tau_{v}$ and the mean amplitude of the diurnal cycle $\overline{\mathrm{P}}_{\mathrm{DC}}$ for islands (in class $\mathrm{A} 1$ to $\mathrm{A} 3$ ). Colors indicate the enhancement of precipitation in the center of the island respective to the surrounding ocean expressed by their difference: $\Delta \overline{\mathrm{P}}=\overline{\mathrm{P}_{\mathrm{c}}}$ $\overline{\mathrm{P}_{\mathrm{o}}}$; marker sizes indicate the island area class (small: A1; medium: A2; large: A3).

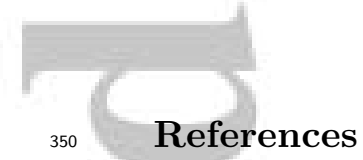

${ }_{351} \quad$ Amante, C., \& Eakins, B. W. (2009). Etopo1 1 arc-minute global relief model: 352 procedures, data sources and analysis. us department of commerce, national 353 oceanic and atmospheric administration, national environmental satellite, data, $354 \quad$ and information service, national geophysical data center. Marine Geology and Geophysics Division, 19.

Atlas, R., Hoffman, R. N., Ardizzone, J., Leidner, S. M., Jusem, J. C., Smith, D. K., ${ }_{357}^{356} \quad \&$ Gombos, D. (2011). A cross-calibrated, multiplatform ocean surface wind 358 velocity product for meteorological and oceanographic applications. Bulletin of 359 the American Meteorological Society, 92(2), 157-174.

$360 \quad$ Carbone, R., Wilson, J., Keenan, T., \& Hacker, J. (2000). Tropical island convection 361 in the absence of significant topography. part i: Life cycle of diurnally forced 362 convection. Monthly weather review, 128(10), 3459-3480.

363 Coppin, D., \& Bellon, G. (2019a). Physical mechanisms controlling the offshore 364 propagation of convection in the tropics. part i: Flat island. Journal of Advances in Modeling Earth Systems.

Coppin, D., \& Bellon, G. (2019b). Physical mechanisms controlling the offshore propagation of convection in the tropics. part ii: Influence of topography. Jour-

${ }_{368}^{367}$ nal of Advances in Modeling Earth Systems.

${ }_{369}$ Cronin, T. W., Emanuel, K. A., \& Molnar, P. (2015). Island precipitation enhance370 ment and the diurnal cycle in radiative-convective equilibrium. Quarterly Jour371 nal of the Royal Meteorological Society, 141(689), 1017-1034.

${ }_{372}$ Dailey, P. S., \& Fovell, R. G. (1999). Numerical simulation of the interaction be-

373 tween the sea-breeze front and horizontal convective rolls. part i: Offshore

${ }_{374} \quad$ ambient flow. Monthly weather review, 127(5), 858-878.

Fovell, R. G. (2005). Convective initiation ahead of the sea-breeze front. Monthly 
$376 \quad$ weather review, 133(1), 264-278.

377

378

379

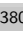

381

382

383

384

385

Fovell, R. G., \& Dailey, P. S. (2001). Numerical simulation of the interaction between the sea-breeze front and horizontal convective rolls. part ii: Alongshore ambient flow. Monthly weather review, 129(8), 2057-2072.

Hagos, S. M., Zhang, C., Feng, Z., Burleyson, C. D., De Mott, C., Kerns, B., ... Martini, M. N. (2016). The impact of the diurnal cycle on the propagation of $\mathrm{m}$ adden-j ulian o scillation convection across the $\mathrm{m}$ aritime $\mathrm{c}$ ontinent. Journal of Advances in Modeling Earth Systems, 8(4), 1552-1564.

Hassim, M., Lane, T., \& Grabowski, W. (2016). The diurnal cycle of rainfall over new guinea in convection-permitting wrf simulations. Atmospheric Chemistry and Physics, 16(1), 161-175.

Janowiak, J. E., Kousky, V. E., \& Joyce, R. J. (2005). Diurnal cycle of precipitation determined from the cmorph high spatial and temporal resolution global precipitation analyses. Journal of Geophysical Research: Atmospheres, 110(D23).

Joyce, R. J., Janowiak, J. E., Arkin, P. A., \& Xie, P. (2004). Cmorph: A method that produces global precipitation estimates from passive microwave and infrared data at high spatial and temporal resolution. Journal of Hydrometeorology, 5(3), 487-503.

Kikuchi, K., \& Wang, B. (2008). Diurnal precipitation regimes in the global tropics. Journal of Climate, 21(11), 2680-2696.

Kingsmill, D. E. (1995). Convection initiation associated with a sea-breeze front, a gust front, and their collision. Monthly weather review, 123(10), 2913-2933.

Lane, T. P., Reeder, M. J., \& Clark, T. L. (2001). Numerical modeling of gravity wave generation by deep tropical convection. Journal of the atmospheric sciences, 58(10), 1249-1274.

Lane, T. P., \& Zhang, F. (2011). Coupling between gravity waves and tropical convection at mesoscales. Journal of the Atmospheric Sciences, 68(11), 25822598 .

Liang, Z., \& Wang, D. (2017). Sea breeze and precipitation over hainan island. Quarterly Journal of the Royal Meteorological Society, 143(702), 137-151.

Liang, Z., Wang, D., Liu, Y., \& Cai, Q. (2017). A numerical study of the convection triggering and propagation associated with sea breeze circulation over hainan island. Journal of Geophysical Research: Atmospheres, 122(16), 8567-8592.

Love, B. S., Matthews, A. J., \& Lister, G. M. (2011). The diurnal cycle of precipitation over the maritime continent in a high-resolution atmospheric model. Quarterly Journal of the Royal Meteorological Society, 137(657), 934-947.

Majda, A. J., \& Yang, Q. (2016). A multiscale model for the intraseasonal impact of the diurnal cycle over the maritime continent on the madden-julian oscillation. Journal of the Atmospheric Sciences, 73(2), 579-604.

Mapes, B. E., Warner, T. T., \& Xu, M. (2003). Diurnal patterns of rainfall in northwestern south america. part iii: Diurnal gravity waves and nocturnal convection offshore. Monthly weather review, 131(5), 830-844.

Mori, S., Jun-Ichi, H., Tauhid, Y. I., Yamanaka, M. D., Okamoto, N., Murata, F., ... Sribimawati, T. (2004). Diurnal land-sea rainfall peak migration over sumatera island, indonesian maritime continent, observed by trmm satellite and intensive rawinsonde soundings. Monthly Weather Review, 132(8), 2021-2039.

Neale, R., \& Slingo, J. (2003). The maritime continent and its role in the global climate: A gcm study. Journal of Climate, 16(5), 834-848.

Ogino, S.-Y., Yamanaka, M. D., Mori, S., \& Matsumoto, J. (2016). How much is the precipitation amount over the tropical coastal region? Journal of Climate, 29(3), 1231-1236.

Ogino, S.-Y., Yamanaka, M. D., Mori, S., \& Matsumoto, J. (2017). Tropical coastal dehydrator in global atmospheric water circulation. Geophysical Research Letters, $44(22), 11-636$.

Peatman, S. C., Matthews, A. J., \& Stevens, D. P. (2014). Propagation of the 
$431 \quad$ madden-julian oscillation through the maritime continent and scale interac-

432 tion with the diurnal cycle of precipitation. Meteorological Society, 140 (680), 814-825.

Planchon, O., Damato, F., Dubreuil, V., \& Gouéry, P. (2006). A method of identifying and locating sea-breeze fronts in north-eastern brazil by remote sensing. Meteorological Applications, 13(3), 225-234.

Rani, S. I., Ramachandran, R., Subrahamanyam, D. B., Alappattu, D. P., \& Kunhikrishnan, P. (2010). Characterization of sea/land breeze circulation along the west coast of indian sub-continent during pre-monsoon season. Atmospheric Research, 95(4), 367-378.

Saito, K., Keenan, T., Holland, G., \& Puri, K. (2001). Numerical simulation of the diurnal evolution of tropical island convection over the maritime continent. Monthly weather review, 129(3), 378-400.

Schiemann, R., Demory, M.-E., Mizielinski, M. S., Roberts, M. J., Shaffrey, L. C., Strachan, J., \& Vidale, P. L. (2014). The sensitivity of the tropical circulation and maritime continent precipitation to climate model resolution. Climate dynamics, 42(9-10), 2455-2468.

Sobel, A. H., Burleyson, C., \& Yuter, S. (2011). Rain on small tropical islands. Journal of Geophysical Research: Atmospheres, 116(D8).

Suresh, R. (2007). Observation of sea breeze front and its induced convection over chennai in southern peninsular india using doppler weather radar. In Atmospheric and oceanic (pp. 1511-1525). Springer.

Tulich, S. N., Randall, D. A., \& Mapes, B. E. (2007). Vertical-mode and cloud decomposition of large-scale convectively coupled gravity waves in a twodimensional cloud-resolving model. Journal of the atmospheric sciences, 64(4), 1210-1229.

Wang, S., \& Sobel, A. H. (2017). Factors controlling rain on small tropical islands: Diurnal cycle, large-scale wind speed, and topography. Journal of the Atmospheric Sciences, 74 (11), 3515-3532.

Wu, P., Mori, S., Hamada, J.-I., Yamanaka, M. D., Matsumoto, J., \& Kimura, F. (2008). Diurnal variation of rainfall and precipitable water over siberut island off the western coast of sumatra island. SOLA, 4, 125-128.

Yang, G.-Y., \& Slingo, J. (2001). The diurnal cycle in the tropics. Monthly Weather Review, 129(4), 784-801.

Zhou, L., \& Wang, Y. (2006). Tropical rainfall measuring mission observation and regional model study of precipitation diurnal cycle in the new guinean region. Journal of Geophysical Research: Atmospheres, 111(D17).

Zhu, L., Z, M., F, Z., \& PM, M. (2017). The influence of sea-and land-breeze circulations on the diurnal variability in precipitation over a tropical island. Atmospheric chemistry and physics, 17.

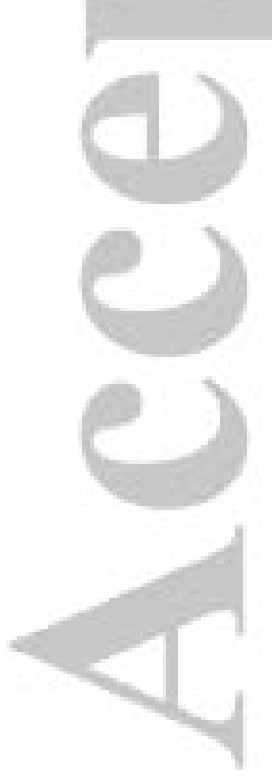


Figure 1.
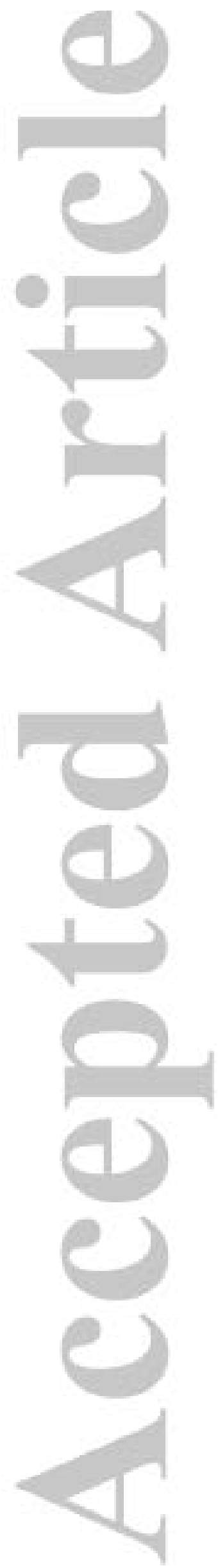

(C2019 American Geophysical Union. All rights reserved. 
a) Mean Daily Precpitation

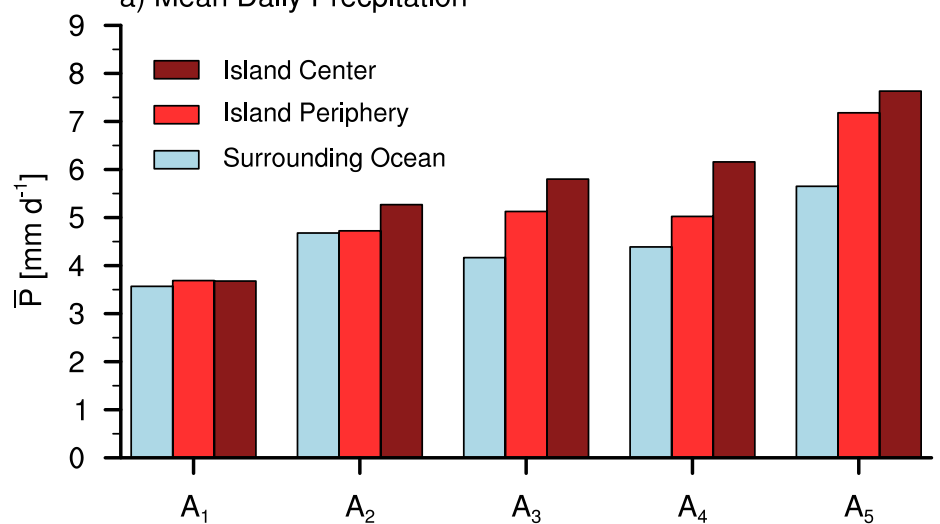

b) Diurnal Cycle - Island Periphery

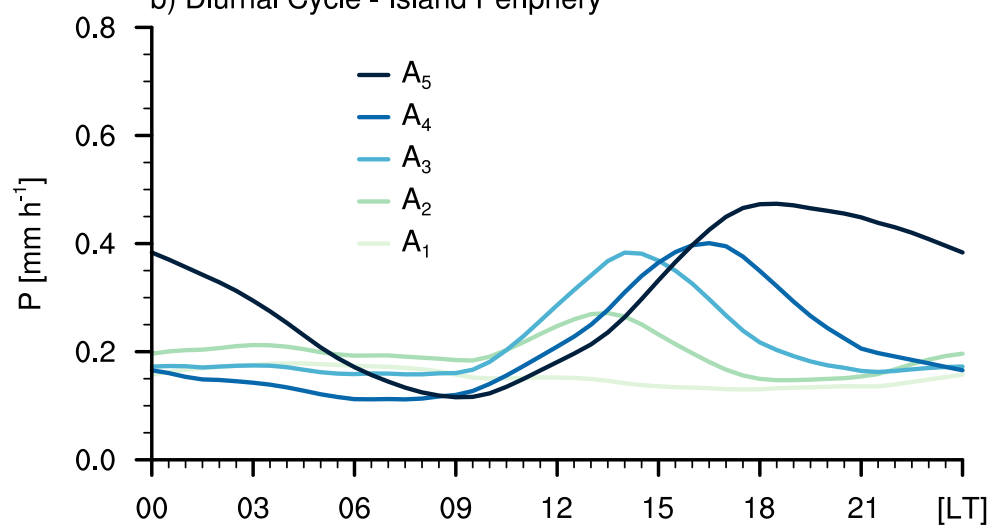

c) Diurnal Cycle - Island Center

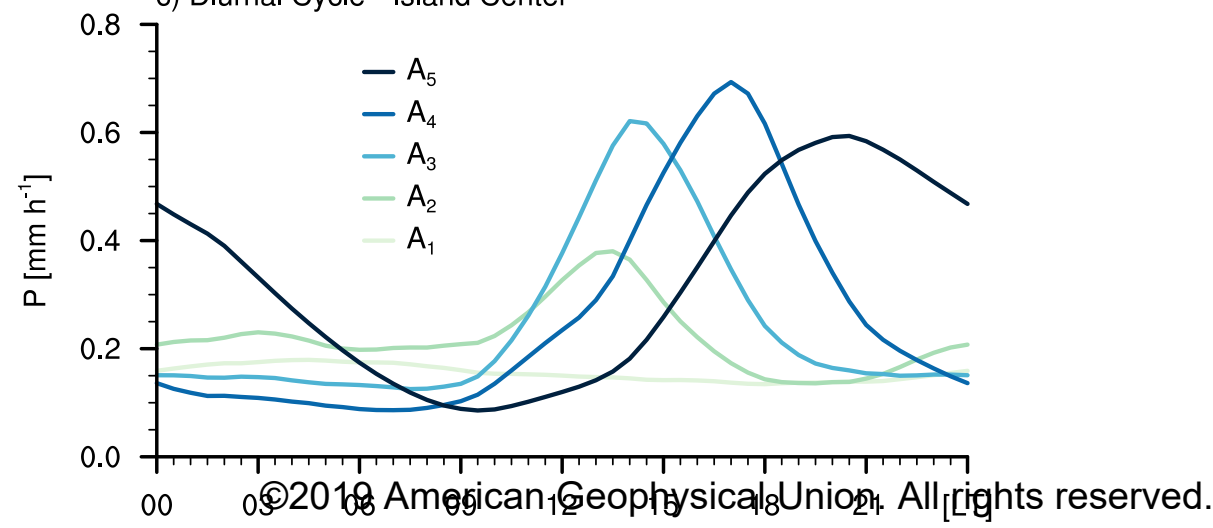


Figure 2.
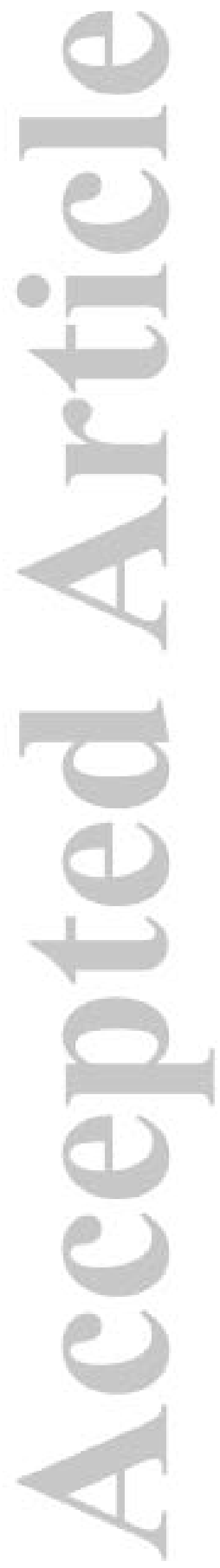

(C2019 American Geophysical Union. All rights reserved. 

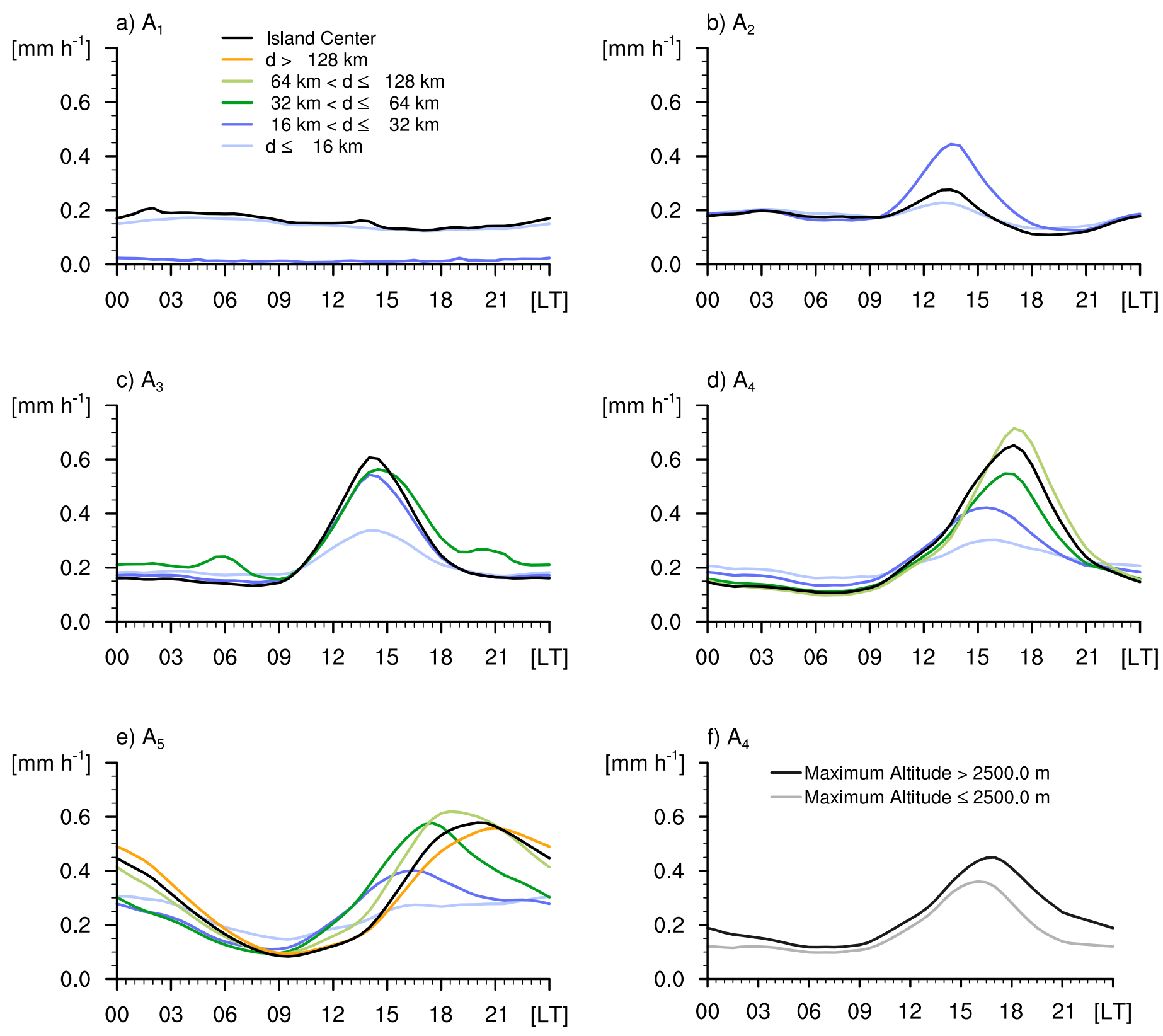

(C2019 American Geophysical Union. All rights reserved. 
Figure 3.
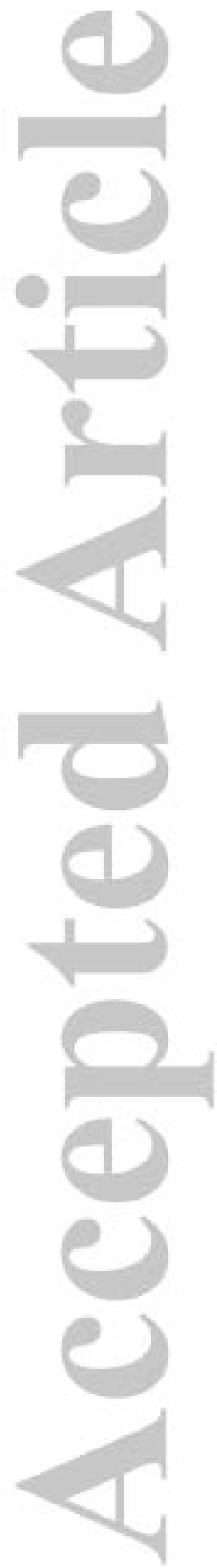

(C2019 American Geophysical Union. All rights reserved. 


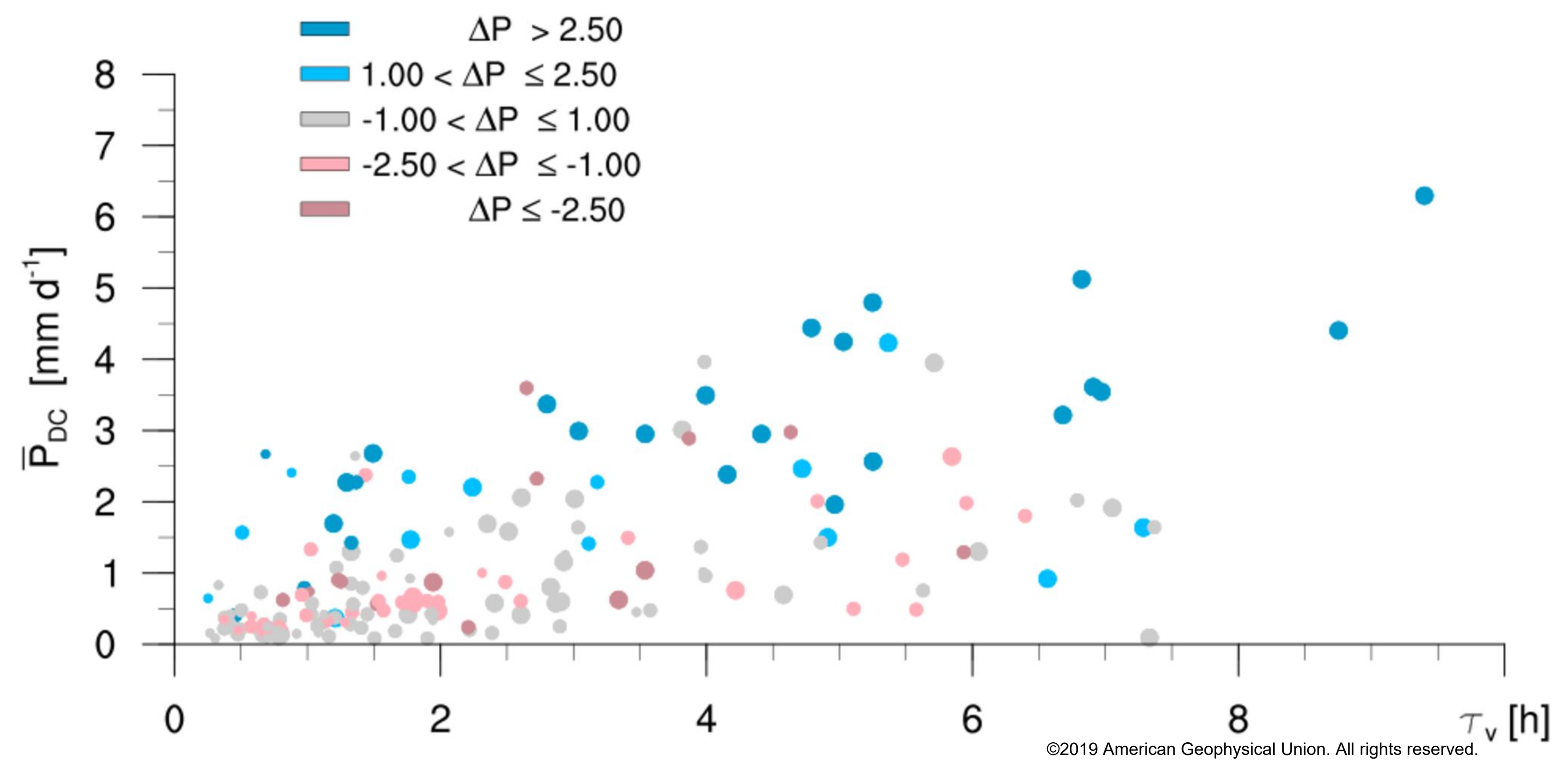

